\title{
Correlation between genetic heterogeneity and variability for response to growth hormone in Noonan syndrome
}

\author{
Young-Lim Shin, MD \\ Department of Pediatrics, Soonchunhyang University Bucheon Hospital, Soonchunhyang University College of Medicine, Bucheon, Korea
}

Noonan syndrome (NS) is a relatively common autosomal dominant disorder characterized by short stature, dysmorphic facial features, congenital heart disease, cryptorchidism, and mild learning disabilities. ${ }^{1,2)}$ Short stature is a common clinical feature in more than $50 \%$ of NS patients. ${ }^{2)}$ Birth weight and length in NS are usually within normal ranges, followed by a progressive growth failure until puberty. Pubertal development is generally delayed and pubertal growth shows a low peak. ${ }^{3)}$

NS is a genetically heterogeneous disorder with germline mutations affecting the RASmitogen-activated protein kinase (RAS-MAPK) signal transduction pathway, leading to dysregulation. ${ }^{4)}$ NS has variable clinical features and genetic complexity caused by mutations in several genes including PTPN1 1, SOS1, RAF1, KRAS, NRAS, SHOC2, CBL, BRAF, SOS2, RIT1, RRAS, RASA2, SPRY1, LZTR1, MAP3K8, MYST4, and A2ML1. H) However, genetic mutations have not been identified in 20\%-30\% of all patients with NS.

The majority of NS patients (40\%-50\%) have a mutation in the protein tyrosine phosphatase non-receptor type 11 (PTPN1 1) gene that encodes the protein tyrosine phosphatase, Src homology region 2-domain phosphatase-2 (SHP-2). ${ }^{1)}$ This PTPN1 1 mutation results in a gain of function of SHP-2, which acts on the growth hormone (GH) receptor signaling pathway as a negative regulator. SOS1 mutations, the second most common cause of NS, are observed in approximately 10\%-20\% of cases. ${ }^{6)}$ RAF1 and RIT1 mutations have a similar prevalence (8\%)." PTPN1 1, SOS1, RAF1, and RIT1 comprise 93\% of reported mutations. ${ }^{\text {7) }}$

The causes of growth disturbances in NS were reported as many different mechanisms, including GH deficiency, GH insensitivity, and neurosecretory dysfunction. ${ }^{1,8)} \mathrm{GH}$ treatment efficacy is under debate. ${ }^{9)}$ It is difficult to systematically compare published data about GH treatment in NS due to heterogeneous protocols, some bias, insufficient numbers of subjects, different cohort selection, and short-term therapy. ${ }^{10,11)}$

Several studies have compared GH treatment efficacy between PTPN11 mutation-positive and mutation-negative patients. ${ }^{8)}$ A number of studies reported that the height standard deviation scores of patients without a PTPN1 1 mutation were significantly increased compared to those with PTPN1 1 mutations after 1, 2, and 3 years of GH therapy. ${ }^{8)}$ NS patients with PTPN1 1 mutations may have lower insulin-like growth factor-1 levels and higher serum GH levels, suggestive of mild GH resistance compared to patients without a PTPN1 1 mutation. ${ }^{8}$

It is important that GH therapy is started at a younger age, namely before the onset of delayed puberty. It is also believed that a prepubertal start of GH therapy could compensate for the lack of a pubertal growth spurt. ${ }^{5}$ Most researchers asserted that prepubertal status and early initiation of therapy are essential predictors in GH response ${ }^{4)}$, however, few studies have reported. Binder ${ }^{11)}$ demonstrated a trend toward a higher first-year growth rate in prepubertal NS children without the PTPN1 1 mutation. In this regard, the study of Jo et al. ${ }^{12)}$ is considered valuable because it compared early GH effects in prepuberty between patients with and those
Corresponding author: Young-Lim Shin, MD Department of Pediatrics, Soonchunhyang University Bucheon Hospital, 170 Jomaru-ro, Wonmi-gu, Bucheon 14584, Korea

Tel: +82-32-621-5407

Fax: +82-32-621-5016

E-mail: ylshin@schmc.ac.kr

https://orcid.org/0000-0002-4327-4517

Received: 4 March, 2019

Revised: 14 June, 2019

Accepted: 2 July, 2019

See the article "Comparison of effectiveness of growth hormone therapy according to diseasecausing genes in children with Noonan syndrome" in Volume 62 on page 274.

Copyright $(2019$ by The Korean Pediatric Society

This is an open-access article distributed under the terms of the Creative Commons Attribution NonCommercial License (http://creativecommons.org/ licenses/by-nc/4.0/n which permits unrestricted noncommercial use, distribution, and reproduction in any medium, provided the original work is properly cited. 
without NS-causing gene mutations. The association between shortterm growth response and genotype seems unsuitable for an analysis of GH effect in NS. ${ }^{8,13}$ Noordam et al. ${ }^{13)}$ reported that the response to GH treatment for 3.0-10.3 years was not significantly different in children with PTPN1 1 mutations, compared those without PTPN11 mutations. There are few reports of final height data in GH-treated NS children. Therefore, there is a lack of evidence that NS patients with the PTPN1 1 mutations have a shorter final adult height.

Another important point is the genetic heterogeneity of the study subjects causes variability in the response to GH therapy. Heterozygous mutations in more than 17 genes are known to underlie NS or NS-related disorders. In the study of Jo et al., ${ }^{12)}$ the response to GH therapy of NS children in PTPN1 1, RAF1, and SOS1 mutation groups were compared to those of NS patients in 5 genes (PTPN11, $R A F 1, S O S 1, K R A S$, and BRAF) undetected (FGU) group. There are several problems with organizing patients with NS without mutations in 5 genes into the FUG group, as patients in the FGU group may have other undetected NS-causing genes. In other words, because the FGU group may include multiple genetic characteristics, its use as a control group is not suitable. Moreover, affected signaling proteins of the RAS-MAPK pathway other than the cytosolic protein tyrosine phosphatase encoded by PTPN1 1 are not completely understood to be directly implicated in the GH signaling pathway. The GH response of patients with NS-causing gene mutations other than PTPN11 has yet to be clarified. ${ }^{10,11)}$ For these reasons, bias may be unavoidable in the analysis of the GH response in the FGU group. Thus, GH responses in very few patients with each gene mutation may not enable a thorough analysis.

The variety of phenotypes in NS represents different genes with diverse mutations. An increased understanding of the causes of short stature in NS such as RAS-MAPK pathway dysregulation is necessary. In patients with diverse mutations in NS-causing genes, reliable large-scale and case-control studies are crucial in elucidating the long-term effects of GH treatment.

\section{Conflicts of interest}

No potential conflict of interest relevant to this article was reported.

\section{References}

1. Roberts AE, Allanson JE, Tartaglia M, Gelb BD. Noonan syndrome. Lancet 2013;381:333-42.

2. Romano AA, Allanson JE, Dahlgren J, Gelb BD, Hall B, Pierpont ME, et al. Noonan syndrome: clinical features, diagnosis, and management guidelines. Pediatrics 2010;126:746-59.

3. Ranke MB, Heidemann P, Knupfer C, Enders H, Schmaltz AA, Bierich JR. Noonan syndrome: growth and clinical manifestations in 144 cases. Eur J Pediatr 1988;148:220-7.

4. Noonan JA, Kappelgaard AM. The efficacy and safety of growth hormone therapy in children with noonan syndrome: a review of the evidence. Horm Res Paediatr 2015;83:157-66.

5. Tajan M, Paccoud R, Branka S, Edouard T, Yart A. The RASopathy Family: consequences of germline activation of the RAS/MAPK Pathway. Endocr Rev 2018;39:676-700.

6. Tartaglia M, Pennacchio LA, Zhao C, Yadav KK, Fodale V, Sarkozy A, et al. Gain-of-function SOS1 mutations cause a distinctive form of Noonan syndrome. Nat Genet 2007;39:75-9.

7. El Bouchikhi I, Belhassan K, Moufid FZ, Iraqui Houssaini M, Bouguenouch L, Samri I, et al. Noonan syndrome-causing genes: molecular update and an assessment of the mutation rate. Int $\mathrm{J}$ Pediatr Adolesc Med 2016;3:133-42.

8. Binder G, Neuer K, Ranke MB, Wittekindt NE. PTPN11 mutations are associated with mild growth hormone resistance in individuals with Noonan syndrome. J Clin Endocrinol Metab 2005;90:5377-81.

9. Choi JH, Lee BH, Jung CW, Kim YM, Jin HY, Kim JM, et al. Response to growth hormone therapy in children with Noonan syndrome: correlation with or without PTPN11 gene mutation. Horm Res Paediatr 2012;77:388-93.

10. Tamburrino F, Gibertoni D, Rossi C, Scarano E, Perri A, Montanari F, et al. Response to long-term growth hormone therapy in patients affected by RASopathies and growth hormone deficiency: Patterns of growth, puberty and final height data. Am J Med Genet A 2015; 167A:2786-94.

11. Binder G. Noonan syndrome, the Ras-MAPK signalling pathway and short stature. Horm Res 2009;71 Suppl 2:64-70.

12. Jo KJ, Kim YM, Yoon JY, Lee YJ, Han YM, Yoo HW, et al. Comparison of effectiveness of growth hormone therapy according to diseasecausing genes in children with Noonan syndrome. Korean J Pediatr 2019;62:274-80.

13. Noordam C, Peer PG, Francois I, De Schepper J, van den Burgt I, Otten BJ. Long-term GH treatment improves adult height in children with Noonan syndrome with and without mutations in protein tyrosine phosphatase, non-receptor-type 11. Eur J Endocrinol 2008;159:2038. 